BULLETIN Bulletin hispanique

HISPANIQUE Université Michel de Montaigne Bordeaux

$112-2 \mid 2010$

Varia

\title{
Luis de Góngora, Antología poética
}

Crítica, Barcelona, 2009

Jacques Issorel

\section{OpenEdition}

Journals

Édition électronique

URL : http://journals.openedition.org/bulletinhispanique/1289

DOI : 10.4000/bulletinhispanique.1289

ISSN : $1775-3821$

Éditeur

Presses universitaires de Bordeaux

\section{Édition imprimée}

Date de publication : 31 décembre 2010

Pagination : 847-849

ISBN : 978-2-86781-709-0

ISSN : 0007-4640

Référence électronique

Jacques Issorel, « Luis de Góngora, Antología poética », Bulletin hispanique [En ligne], 112-2 | 2010, mis en ligne le 19 janvier 2013, consulté le 01 mai 2019. URL : http://journals.openedition.org/

bulletinhispanique/1289 
Luis de Góngora, Antología poética. Antonio Carreira (ed.) - Barcelona, Crítica, 2009, 711 p. (Clásicos y Modernos, 30).

L'œuvre de Luis de Góngora connut un singulier destin. Portée aux nues par les uns, blâmée par les autres du vivant du poète, victime de la censure un an après sa mort (saisie de l'édition de Juan Vicuña), avant d'être de nouveau publiée (1633), elle suscita, comme aucune autre, une longue série de commentaires savants de 1613 (Pedro de Valencia) à 1666 (Enrique Vaca de Alfaro Gómez). Puis, deux siècles s'écoulèrent, au cours desquels elle fut vilipendée et, dans le meilleur des cas, ignorée. Ce n'est qu'à la charnière des $\mathrm{XIX}^{\mathrm{e}}$ et $\mathrm{XX}^{\mathrm{e}}$ siècles avec Rubén Darío et l'hispaniste Raymond FoulchéDelbosc, et surtout à l'occasion du tricentenaire de la mort du poète qu'elle resurgit, superbement défendue par un groupe de jeunes poètes : Federico García Lorca, Gerardo Diego, Jorge Guillén, Pedro Salinas, Rafael Alberti ${ }^{14}$ et particulièrement Dámaso Alonso, auteur de magistrales études et d'éditions grâce auxquelles le poète cordouan retrouva prestige et audience. Robert Jammes et Antonio Carreira ont été parmi ceux qui, après Dámaso Alonso, ont le mieux contribué, au cours de ces cinquante dernières années, à rendre l'œuvre de Góngora à la fois plus accessible et encore plus attrayante. De la dernière et récente publication de Jammes il sera question dans le compte rendu suivant. Tout aussi récente est l'Antología poética préparée par Carreira. Elle réunit 200 poèmes, parmi lesquels le Polyphème et les Solitudes dans leur intégralité. Chaque poème est accompagné de notes abondantes et, pour la plupart, d'un commentaire qui situe le texte et en éclaire finement le sens. On a donc le plaisir de trouver dans ce fort volume les romances, letrillas, chansons, sonnets, tercets, les plus connus et étudiés de Góngora à côté d'autres textes moins connus et qui ne figuraient pas dans la précédente anthologie du poète publiée par Carreira en 1986 (Castalia), laquelle ne comptait que 80 poèmes et 372 pages.

Comme l'explique l'auteur dans l'introduction (p. 7-33), Góngora avait lui-même revu à la fin de sa vie, avec l'aide de son ami Antonio Chacón, le manuscrit qui porta désormais le nom de ce dernier, en indiquant "con extremo cuidado fecha, asunto y a veces circunstancias de sus poemas ", p. 27 (v. g. "Infiere, de los achaques de la vejez, cercano el fin a que católico se alienta", p. 634). Aussi Carreira a-t-il pris soin de conserver l'ordre chronologique de composition dans la présentation des poèmes, grâce auquel " [pasamos],

14. Gerardo Diego et Rafael Alberti composèrent à cette occasion des poèmes de style gongorin : Fábula de Equis y Zeda et Soledad tercera (inachevée). Ajoutons-y le beau poème, écologique avant la lettre, de Fernando Villalón : La Toriada (Málaga, 1928). 
sin darnos cuenta, de lectores de la obra a espectadores de la vida y evolución estilistica de uno de nuestros mayores poetas " (p. 32). Bien que plus brève que celle de la précédente anthologie, l'introduction de la nouvelle n'en est pas moins pertinente et instructive. Carreira y balaie de la main les qualificatifs de "barroco " et "culterano " dont on a erronément, de génération en génération, affublé la poésie gongorine pour redire, comme déjà en leur temps l'avaient fait Lope de Vega et Gracián, qu'elle est l'exemple le plus abouti de la poésie conceptiste : "Góngora se hizo maestro del concepto por la coherencia con que lo mantiene y la eficacia verbal de que lo dota" (p. 25). Il met en relief plusieurs des traits principaux de l'écriture du poète. Ainsi la "polaridad de popular y culto" (p. 11) que l'on remarque dès les poèmes de jeunesse et dont la fusion constituera jusqu’à la fin l'une des «marques de fabrique » de Góngora.

Parallèlement à celle-ci, une autre dualité est présente tout au long de l'œuvre : "el poeta serio y el festivo " (ibid.). Le sonnet " De la jornada de Larache " (p. 285) et celui intitulé "De la toma de Larache " (1 ${ }^{\text {er }}$ vers : "La fuerza que infestando las ajenas ", Obras completas, I, ed. y pról. de Antonio Carreira, Madrid, Fundación José Antonio de Castro, 2000, p. 300) en est le parfait exemple. Tout aussi surprenante pour ses contemporains, et motif de louange pour les uns et de réprobation pour les autres, fut l'adoption par Góngora d'un "fastuoso lenguaje " (p. 13) jusque-là réservé aux sujets dits nobles pour chanter la beauté des choses simples : les animaux de bassecour, le fromage, les pommes ou le vin. "Góngora es un enamorado de la vida, un vividor " (p. 21), écrit Carreira, qui accompagne cette affirmation du commentaire de quatre passages des Soledades ${ }^{15}$. C'est, bien sûr, à cette œuvre majeure, déjà par lui longuement étudiée dans Gongoremas (chap. III, "Las Soledades", Barcelona, Península, 1998, p. 223-313), qu'il consacre une partie importante de son introduction. Si, dès leur lecture dans les cercles cultivés de Cordoue et de Madrid, les Soledades suscitèrent des réactions si diverses, c'est bien parce qu'elles bousculaient les habitudes et brisaient les routines : l'originalité du sujet, le jeu des rimes, tantôt proches, tantôt lointaines, les registres variés, les libertés que permettait la silva, les audaces syntaxiques (" añoranza de la sintaxis latina ", p. 16), tout contribuait à en faire un poème novateur. Conscient d'apporter à la langue littéraire un air nouveau, une "aura de libertad» (p. 16), Góngora put écrire dans sa fameuse lettre du 30 septembre 1613, "en respuesta de la que le escribieron", que

15. Le commentaire des quatre premiers vers de la « Dedicatoria » mérite une particulière attention (p. 15-16). 
grâce à son travail la langue espagnole avait atteint "la perfección y alteza de la latina" (p. 16).

À plusieurs reprises enfin, Carreira souligne la musicalité de la poésie gongorine et opère un rapprochement entre le "sistema de leyes [musicales]" des vers du poète et celui qui préside aux compositions de Schubert et de Mahler (p. 16). Une "Bibliografía selecta ", et néanmoins riche (p. 35-65), et un fort utile "Índice de notas" (p. 667-692) complètent ce bel ouvrage agrémenté de neuf illustrations. Judicieusement choisie, la photo de couverture renvoie aux vers 49-50 de la Première Solitude: "Riscos que aun igualara mal volando / veloz, intrépida ala... " (p. 415).

Jacques IssoreL

Comprendre Góngora. Robert Jammes (trad. et présentation). - Toulouse, Presses universitaires du Mirail, 2009, XV + 357 p. (Anejos de Criticón, 18).

Ce superbe ouvrage se présente sous un format oblong $(17,5 \times 24 \mathrm{~cm})$ tout à fait adapté à l'édition bilingue de textes poétiques. La couverture illustrée, la qualité du papier, la netteté de l'impression, tout concourt au plaisir du lecteur. Les 114 poèmes choisis par Robert Jammes sont imprimés en gras et leur traduction en maigre. Outre le souci de clarté et de confort du lecteur, cette différence traduit visuellement les réserves exprimées par l'auteur dans sa préface : "Rompant avec les habitudes, écrit-il, la présente anthologie bilingue ne propose pas des traductions "avec le texte de Góngora en regard", mais un choix de textes de Góngora avec une traduction en marge " (p. XIII). Dans la notice d'introduction aux Soledades, après avoir expliqué que traduire cette œuvre majeure est une entreprise désespérée, il définit modestement son texte comme un simple "marchepied [...] pour prendre possession des Soledades - en espagnol» (p. 220). La lecture concomitante des poèmes et des traductions révèle que le traducteur n'a pas dérogé à son intention de "docile exactitude » (p. XIII). Autrement dit, il cherche non pas à briller mais à aider le lecteur à découvrir dans tout leur éclat les "trésors de la forteresse " gongorine (ibid.). Il y réussit d'autant mieux qu'il conserve la prosodie des vers de Góngora en traduisant en heptasyllabes romances et décimas, en pentasyllabes romancillos et letrillas, et en décasyllabes les hendécasyllabes. 